\title{
COMPOSTO MERCADOLÓGICO NO VAREJO DE CARNE BOVINA
}

\author{
Marketing mix in the beef retail \\ Haroldo de Sá Medeiros', Mariluce Paes-de-Souza², Theophilo Alves de Souza Filho³ \\ I Professor da Universidade Federal de Rondônia. \\ 2 Professor da Universidade Federal de Rondônia. \\ 3 Professor da Universidade Federal de Rondônia.
}

\section{Resumo}

Este artigo tem por objetivo analisar a percepção de valor de compradores de carne bovina, in natura, a partir dos compostos mercadológicos considerados pelos clientes no processo de compra, em empresas do segmento supermercadista de Porto Velho-RO, visando propor um modelo de composto mercadológico direcionado ao varejo de carne bovina. Para tal, foi analisada a percepção de valor dos compradores de carne bovina e foram conhecidos quais elementos do composto mercadológico varejista eram considerados no ato da compra. Além disso, foram analisados quais elementos influenciam o comportamento de compra dos consumidores. A metodologia empregada neste estudo tem natureza quali-quantitativa e abordagem descritiva. A coleta de dados ocorreu por meio de questionários aplicados a 316 pessoas. A fim de atender o objetivo, o método utilizado foi a análise fatorial. A estrutura subjacente ao composto mercadológico varejista, quando este é relacionado à comercialização da carne bovina, foi evidenciada. Estas estruturas são dadas por oito fatores, que são: comunicação, atendimento, acesso, preço, produto, higiene e decoração, layout e consistência.

Palavras-chave: composto mercadológico, carne bovina, marketing.

\begin{abstract}
This article aims to analyze the value perception of fresh beef buyers from marketing mix considered by customers in the buying process companies in the supermarket segment of Porto Velho-RO, aiming at proposing a model of marketing mix targeted at retail beef. To this, were analyzed the perception of value buyers of beef and acquaintances which elements of the retail marketing mix were considered upon purchase. Furthermore, we analyzed which elements influence the buying behavior of consumers. The methodology used in this study is qualitative- quantitative and the approach is descriptive. The data collection occurred through questionnaires given to 316 people. In order to meet the objective, the method used was the factorial analysis. The underlying structure retail marketing mix, when it is related to marketing of beef, was found. These structures are given for eight factors, which are: communication, attendance, access , price, product, hygiene and decoration, layout and consistency.
\end{abstract}

Key-words: marketing mix, beef, marketing. 


\section{INTRODUÇÃO}

Mudanças expressivas têm ocorrido no comportamento dos consumidores, nos últimos anos, em diversas áreas, entre elas a da alimentação. O hábito alimentar transformou-se e as dificuldades de transporte, ganho de tempo, entre outros fatores, forçam as pessoas a comprar alimentos que facilitem seu dia a dia. Qualidade do produto, rapidez no atendimento, comodidade, uso de tecnologia e diversos outros aspectos deixaram de ser diferenciais e tornaram-se elementos básicos para atrair e manter compradores.

A fim de se diferenciar da concorrência, empresas têm implementado ações que pretendem oferecer facilidade aos compradores. $\mathrm{O}$ varejo, conector de produtores e consumidores, na busca pela fidelização dos consumidores e pela manutenção de suas vantagens competitivas, tem sido levado a empregar estratégias mais focadas no cliente, tornando-se um importante elemento do marketing (Las casas, 2007; Praxedes, 2007). Atrelado aos conceitos de marketing de varejo e as ferramentas relacionadas a esse tema, autores como Kotler (2009) e Gosling (2007) destacam o marketing de experiência. Esse conceito, oriundo das relações B2B (business to business), liga valores ao produto que não estão diretamente presos à mercadoria durante o ato da compra nas relações B2C (business to consumer). Dessa forma, a empresa pode influenciar o consumidor a partir de ações que valorizam a própria empresa e não somente seus produtos comercializados.

Dentre as relações entre o segmento varejista e a cadeia da bovinocultura de corte, destacam-se os supermercados. Tal modelo de negócio se destaca por ocupar um papel importante, agindo como comprador e distribuidor de carne bovina, além de ser um dos principais agentes de mudanças da cadeia devido a seu crescente poder de compra e barganha frente aos outros componentes (Neves, 2000). A compreensão por parte das empresas do setor de supermercados em relação às necessidades e desejos dos consumidores é diferenciada, pois dessemelhante a outros setores do varejo, especialmente aqueles em que as lojas são de pequeno porte, este oferta um grande número de itens e, no caso da carne bovina, a baixa diferenciação do produto torna dificultosas as práticas mercadológicas que visam influenciar o cliente. Desta forma, este artigo tem por objetivo analisar a percepção de valor de compradores de carne bovina, in natura, a partir dos compostos mercadológicos considerados pelos clientes no processo de compra em empresas do segmento supermercadista de Porto Velho-RO, visando propor um modelo de composto mercadológico direcionado ao varejo de carne bovina.

\section{REFERENCIAL TEÓRICO}

A competitividade no mercado, a disputa por clientes em um ambiente mutável e o surgimento de concorrentes demanda das empresas um esforço por meio de ações mercadológicas que possam ser modificadas, ao longo do tempo, para atender expectativas ou tendências oriundas dos desejos do consumidor. Não obstante, no segmento varejista, nos últimos anos houve a popularização das franquias, o crescimento de grandes redes e a ascensão do uso da internet para compras, trazendo uma nova discussão sobre o composto mercadológico praticado no segmento (Silveira et Sinem, 2009).

A antiga concepção do composto, proposto por Neil Borden em seu artigo The Concept of the Marketing Mix, publicado em 1964, posteriormente adaptado e simplificado por Jerome Mccarthy, ainda na década de 1960, com o famoso conceito dos 4P's (preço, produto, praça ou ponto de venda e promoção) e difundido por Philip Kotler em seus livros, hoje é alvo de críticas por não atender a diversas mudanças ocorridas aos formatos de negócio vigentes (Goi, 2009; Constantinides, 2006). Por isso, na tentativa de ampliar o conceito dos 4P's, outros modelos de composto foram publicados em diversos estudos com a finalidade de preencher, com novas estratégias, lacunas ainda existentes sobre o tema. Tais estratégias são, muitas vezes, voltadas especificamente para um setor, segmento ou serviço. Entre eles podem destacar-se os 4C's do relacionamento - communication, customisation, collaboration, clairvoyance; as quatro chaves do marketing moderno - preço, marca, pacote de valor e relacionamento; mix de marketing de serviços - produto, preço, praça, promoção, processos e pessoas; ou, ainda, o composto mercadológico do e-varejo - convenience, customer value and benefit, cost to consumer, computing and category management, customer franchise, customer care and service e communication and customer relathionships, (Dennis et al., 2005; Constantinides, 2006; Gosling et Souza, 2007).

No varejo com loja física, um dos alvos deste estudo, destaca-se o composto mercadológico varejista proposto por Parente et Barki (2006), também presente por meio de alguns elementos nos estudos de Barki (2005) e Praxedes (2007). Nesse composto estão presentes as estratégias de 
produto, preço, ambiente de loja, localização e acesso, atendimento e comunicação.

Para Kotler (1993), um produto é qualquer coisa que pode ser oferecida a um mercado para aquisição, atenção, utilização ou consumo e que pode satisfazer um desejo ou necessidade. Ainda, para Schewe (1982), os produtos são ofertados por meio de um pacote de utilidade, de forma que um produto inclui cada atividade executada por uma empresa a fim de transmitir satisfação. Dessa forma, é possível concluir que um produto pode ser composto de características tangíveis e intangíveis, incluindo o produto bruto (parte tangível) e serviços (parte intangível). A associação de ambas as características formam o pacote de valor relatado por Schewe (1982), assim, para Kotler (1993), o conjunto destas é determinado por três níveis de um produto:

- Produto básico: concepção e núcleo; definição dos benefícios que serão proporcionados aos consumidores após a aquisição do produto;

- Produto tangível: conjunto de características que proporcionam benefícios aos consumidores, qualidade, características, estilo, nome, embalagem, design, marca, entre outros;

- Produto ampliado: conjunto de benefícios e serviços adicionais atrelados ao produto tangível, instalação, entrega, garantia, serviços pós-venda, entre outros.

A partir dos níveis de produto, diferenciações podem ser atribuídas. Inerente às características intrínsecas da tangibilidade, o nível de diferenciação tem dois extremos: mercadorias e produtos de fácil diferenciação. As mercadorias ou commodities, produtos de difícil diferenciação, assim como a carne bovina, são um grande desafio para o marketing, pois o cliente poderá perceber a qualidade do produto apenas após aquisição ou consumo, já que o design e algumas características visuais são semelhantes entre produtos da mesa categoria. Enquanto isso, os produtos de fácil diferenciação permitem que seus projetos de concepção apresentem demasiada liberdade, de forma que características visuais, design e diversos outros aspectos possam ser atrelados ao produto tangível (Kotler, 2009).

Complementar aos fatores a serem considerados nas estratégias de produto está o gerenciamento de categoria. Segundo Las Casas (2007), o gerenciamento se dá de acordo com o modo que a empresa compreende como o consumidor pensa cada categoria, sendo realizado pela empresa varejista ofertante em parceria com fornecedores. Outro ponto a ser destacado é a reposição de produtos, objetivando a minimização de rupturas das rotinas de compras, na qual o cliente passa a não encontrar determinado item na loja que tinha o hábito de adquiri-lo.

Relacionando os níveis de produto e os fatores que devem ser considerados na elaboração das estratégias, conforme Nascimento (2006), Neves (2000) e Villalobos (2010), os aspectos a serem considerados na oferta da carne bovina in natura são: características tangíveis ligadas à qualidade do produto (cor, cheiro, maciez, embalagem, acondicionamento, indicação de origem e rastreabilidade, frescor) e variedade (sortimento de cortes e marcas). Além desses, a facilidade de preparo da carne após a compra também pode ser considerada.

O preço, como componente mercadológico e econômico, faz-se importante pelo fato de afetar rapidamente a competitividade das empresas. Valores muito elevados e não condizentes com o pacote de valor oferecido podem comprometer negativamente a percepção dos consumidores quanto à imagem da empresa ou, ainda, valores demasiadamente baixos podem desvalorizar o produto e até ter um efeito danoso nas finanças da organização. Segundo Kirsch (2006), criar um apelo baseado em preços baixos pode criar situações devastadoras de debilitação psicológica nos indivíduos, na empresa e lucratividade da indústria que produz determinado produto. Ainda, para Paula (2006), a política de preços estabelecida em uma empresa é um fator de sobrevivência, nela residindo o sucesso nas vendas e sua sustentabilidade. De acordo com Parente et Barki (2006), empresas que adotam estratégias com ênfase em preços baixos praticam preços muito competitivos, ao mesmo tempo diminuindo a importância de outros aspectos do composto, oferecendo, por exemplo, atendimento mais reduzido, variedade mais enxuta, instalações simplórias e limitada gama de serviços.

$\mathrm{Na}$ definição de seus preços, as empresas podem ser orientadas para custos ou valor, embora esperem que seus custos sejam menores do que o preço e margem de contribuição estipulados. A orientação para custos leva em consideração os custos provenientes da aquisição dos produtos, custos operacionais, entre outros. A orientação para custos com base no valor tem, como estimativa, o valor que os clientes estariam dispostos a pagar para adquirir os produtos. Além disso, a elaboração das estratégias de marketing deve considerar os descontos e promoções oferecidos, condições de crédito e prazos de pagamento a serem adotados (Kotler, 2009). 
O modo de definição de preços, na cadeia da bovinocultura de corte, está ligado diretamente com o formato de negócio. No entanto, as promoções ou práticas excessivas de preços baixos afetam toda a cadeia (Binkley et Connor, 1998). Feuz et Umberger (2001) relatam em seu estudo, realizado com 248 respondentes, que os consumidores, ao relacionar qualidade percebida com preços, preferem pagar preços mais elevados para obter maiores níveis de qualidade. Sendo que esta qualidade está intrinsecamente relacionada com os atributos tangíveis do produto (qualidade, características, estilo, nome, embalagem, entre outros).

O ambiente de loja ou atmosfera de loja, segundo alguns autores, é uma fonte de diferenciação que compreende os seguintes aspectos: layout do espaço e ergonomia, música ambiente, cores, materiais do ponto de venda, iluminação, aromas, climatização, organização dos produtos, decoração e fatores humanos (Las casas, 2007; Parente et Barki, 2006; Souza, 2009).

Para Las Casas (2007), há influência do ambiente de loja no processo de escolha dos produtos e interfere na percepção de qualidade, no custo relativo dos produtos e, ainda, afeta na decisão de retorno e recomendação à loja. Além disso, para Parente (2008), os consumidores esperam que suas compras sejam um momento alegre e de entretenimento.

Dentro do segmento varejista, a loja pode ser tratada como um conjunto de zonas com características distintas, nas quais passam mensagens diferentes para diversos tipos de consumidores. Essas mensagens estão ligadas às características dos produtos, no entanto, a forma de comunicação de preços ou organização pode interferir (1999, Underhill apud Souza, 2009). Para Parente et Barki (2006), as lojas direcionadas ao público de baixa renda devem manter seus displays sempre cheios de produtos para passar a mensagem de que há fartura e preços baixos.

Próprio das seções de açougue presentes nos supermercados, alguns fatores ligados ao ambiente de loja são necessários à própria conservação do produto. $\mathrm{O}$ acondicionamento adequado durante a exposição e após a compra garante a qualidade no momento do preparo da carne. Segundo Mazzuchetti et Batalha (2004), a aparência do ponto de venda, para os consumidores de carne, está ligada diretamente à percepção da qualidade do produto e a higiene do local.

Embora ações promocionais sejam um fator atrativo para consumidores, a localização e as formas de acesso também são relevantes para a escolha do local de compra. Para Bortoli (2008), algumas atividades do segmento varejista exigem que a loja possua localização e acesso privilegiados, especialmente aquelas que vendem produtos de conveniência, pois, para o consumidor, há baixa demanda de esforço para localizá-los e adquiri-los. Conforme Kirsch (2009), em pesquisa realizada junto a 125 respondentes, a localização do supermercado é o segundo item mais importante para a escolha da loja.

O desempenho das empresas que compõem o setor supermercadista depende significativamente da sua localização, porque parte significativa das vendas advém de consumidores que moram em regiões geográficas próximas à loja. Essa região é denominada área de influência, estando relacionada diretamente com o tamanho da loja, não estando ligada a densidade populacional da área (Parente et Kato, 2001).

Sob a perspectiva da empresa, a escolha errada da localização pode trazer diversas desvantagens, portanto, para Teixeira (2007), os seguintes pontos devem ser observados ao estabelecer as estratégias:

-Tráfego de pedestres;

- Características da loja quanto sua inserção geográfica (galerias comerciais, centros comerciais, junto a grandes lojas, shopping centers, com estacionamento para clientes);

- Acesso a fluxo de veículos e transporte (quantidade e facilidade de transporte);

-Capacidade competitiva da concorrência, na região;

-Características da região e do local (apoio logístico local), entre outros.

Sob a perspectiva do consumidor, as estratégias de localização e acesso se desdobram em conveniência, tornando produtos mais disponíveis e com facilidade de aquisição (Teixeira, 2007; Kotler, 2009).

O contato face a face e a construção de relacionamento não padronizado são características do consumidor brasileiro. A interação do consumidor é algo constante e possível de exemplificar: feiras, bares e pequenos varejos onde a vizinhança se encontra são comuns independentemente da cidade.

O conceito de atendimento não padronizado advém da ideia que cada consumidor é uma pessoa distinta, com problemas únicos (Parente et Barki, 2006). De modo a exemplificar, diversas empresas do setor alimentício adotaram a ação have it your way (peça do seu jeito), ofertando produtos de acordo com os pedidos feitos pelos seus clientes. Dessa forma, o atendimento pode 
gerar "intimidade" entre empresa e consumidor quando há possibilidade e capacidade de fazer ofertas que atendam exigências específicas dos compradores (Kotler, 2009).

Para Las Casas (2007), alguns dos principais desafios do varejo estão presentes no relacionamento, sendo estes: a necessidade de personalização da oferta, flexibilidade das operações em função do perfil do cliente, habilidade dos funcionários e vendedores em agregar valor à experiência de compra, capacidade de lidar com diferenças culturais, entre outros. Para Praxedes (2007), o atendimento em lojas de varejo é um fator importante para os empresários, pois é possível perceber que um atendimento satisfatório faz com que o cliente retorne à loja mais vezes. Funcionários bem treinados e compatíveis com o perfil da empresa ajudam a desenvolver uma boa imagem da organização perante o mercado. No entanto, para o atendimento eficaz, a força de vendas, além de treinamento formal, depende a cultura da empresa, que poderá desenvolver ações que promovam um atendimento de proximidade e diferenciado (Parente et Barki, 2006; Kotler, 2009).

Atrelado ao atendimento, ambiente de loja e as estratégias de produto estão os serviços. Para Kotler (1993), o conjunto de estratégias de serviço é uma ferramenta-chave da concorrência não baseada em guerra de preços, enquanto, para Cobra (2000), a qualidade do serviço está baseada no estreitamento de relações com os clientes e, ainda, os serviços servem como proteção para a imagem das empresas. Dessa forma, o bom atendimento é um modo de agregar valor aos serviços prestados. Alguns serviços prestados por varejistas são: crédito, assistência técnica, alterações no produto vendido, devolução de mercadorias, estacionamento, instalação e montagem de produtos, serviço de entregas, informações para compras, entre diversos outros.

A simples disponibilidade de um produto ou serviço não implicará em vendas, dessa forma, é preciso estabelecer comunicação com seus potenciais mercados consumidores. A partir desta premissa, a comunicação, como função do marketing, busca evidenciar, aos compradores, como um produto pode ser associado às suas necessidades ou desejos. Assim, a comunicação de marketing se releva de grande importância sobre duas perspectivas: empresas e consumidores. Para as empresas, a comunicação promove produtos e serviços, além de transmitir para os potenciais clientes o interesse em atendê-los. Em contrapartida, os consumidores têm a oportunidade de avaliar novos meios de aquisição de produtos ou serviços, formas de pagamento, datas de compra ou, ainda, o interesse de novas empresas em atendê-los. No segmento varejista brasileiro, segundo Vidaurre et Filho (2003), ocorreu um aumento no uso de ferramentas de marketing promocional a partir da década de 1990, pois houve um aumento significativo na competição, especialmente do setor supermercadista, de empresas estrangeiras no país com a aquisição de empresas locais.

As decisões relevantes às mensagens que comunicam produtos ou serviços devem levar em consideração seis fatores: identificação de público-alvo, objetivos da comunicação, planejamento da mensagem, escolha dos canais de comunicação, seleção da fonte de mensagem, coleta do feedback. Esses seis fatores podem ser expressos por meio de ferramentas de comunicação, que compõem o mix de promoção (Kotler, 1993).

Para o estabelecimento do composto promocional, diversos fatores devem ser considerados, como o tipo de mercado do produto, o estado de aptidão dos potenciais compradores, ciclo de vida do produto e as estratégias adotadas. Dentre as estratégias, duas se destacam: empurrar e puxar (Kotler, 1993).

A estratégia de empurrar consiste uso específico da força de vendas e promoção de vendas para "empurrar" o produto através dos canais de distribuição. Neste caso, há a persuasão dos compradores de forma pessoal e direta. Enquanto isso, a estratégia de puxar versa sobre dirigir atividades de influência a vendas sobre as ferramentas de publicidade e propaganda advindas dos fabricantes para estimular as vendas por meio dos distribuidores. No entanto, essas duas estratégias não são excludentes, podendo ser trabalhadas em conjunto.

\section{PROCEDIMENTOS METODOLÓGICOS}

Este estudo caracteriza-se por ser de natureza descritiva, adotada a abordagem quantitativa e como forma de obtenção de dados o survey. O método de análise empregado foi a análise fatorial. Dentre os 333 questionários aplicados, 316 foram considerados válidos e suscetíveis à análise. A invalidação de alguns questionários se deu pela dualidade de respostas em uma mesma questão e excessiva falta de respostas. A escala utilizada foi tipo likert.

O questionário aplicado foi desenvolvido a fim de conhecer a percepção de valor dos respondentes quanto a cada item que compõe o composto mercadológico varejista, tendo sido este 
relacionado ao segmento de comercialização da carne bovina. Cada item foi descrito a partir dos elementos constados no quadro 1.

O valor do Alfa de Cronbach foi calculado com o uso do Software SPSS 17.0 (Statistical Package for the Social Sciences). O índice calculado, levando em conta todas as questões que compõem o questionário, correspondeu a 0,868 . A relação presente no trabalho é de 11,7 casos por variável, calculada a partir da divisão de casos pela quantidade de questões.

Quadro 1. Composto relacionado a comercialização da carne bovina

\begin{tabular}{|c|c|}
\hline Composto Mercadológico Varejista & Itens \\
\hline Produto & $\begin{array}{c}\text { Qualidade da carne, variedade de cortes, variedade } \\
\text { de marcas, outros produtos associados a carne } \\
\text { bovina (sal, carvão, temperos, etc). }\end{array}$ \\
Preço & $\begin{array}{c}\text { Preços, promoções, formas de pagamento, prazos } \\
\text { de pagamento, formas de pagamento. } \\
\text { Transitar livremente na seção de açougue, higiene, } \\
\text { decoração da seção de açougue, cheiro do ambiente. }\end{array}$ \\
Localização e Acesso deja & $\begin{array}{c}\text { Localização do supermercado, estacionamento, } \\
\text { acesso a transporte público, acesso a táxi. } \\
\text { Açougueiros treinados, cordiais, rapidez no no } \\
\text { atendimento, possibilidade de devolução do } \\
\text { produto. }\end{array}$ \\
\hline Comunicação & $\begin{array}{c}\text { Propaganda de TV e rádio, notícias em jornal } \\
\text { impresso ou revista, internet, banners/outdoors, } \\
\text { panfletos. }\end{array}$ \\
\hline
\end{tabular}

Fonte: Elaborado a partir de Barki et Parente (2006)

\section{ANÁLISE DOS RESULTADOS}

A análise de comunalidades mostrou que algumas variáveis possuem um nível baixo de relação com os fatores, pois seus valores estão abaixo de 0,7 . Porém, não há presença de nenhum valor abaixo de 0,5 ou acima de 1 , assim, conforme Fipecafi (2011) e Hair et al (2009), não há necessidade de exclusão de nenhuma das variáveis. Além disso, pouco mais de $69 \%$ dos fatores pode ser explicada pelas variáveis, sendo isto dado pelas suas variâncias, resultado que demonstra o fato dos fatores terem resultados dentro dos parâmetros aceitáveis relacionados ao método de análise.

As variáveis transitar livremente pela seção de açougue, decoração da seção e açougue e possibilidade de devolução são aquelas com índices menos elevados, enquanto acesso a transporte público, açougueiros cordiais e notícia em jornal impresso ou revista possuem os maiores índices de comunalidade.

Tais valores corroboram com o disposto na tabela 1 , onde as variáveis com altos índices de comunalidade são aquelas com as maiores cargas fatoriais e alto poder de explicação dos fatores em que se fazem presentes, enquanto aquelas com valores baixos tem comportamento oposto.

A matriz de rotação dos fatores, conforme a tabela 1, revelou a existência de oito estruturas subjacentes ao composto mercadológico quando este é associado à comercialização da carne bovina no segmento varejista. O processo de explanação de tais estruturas é dado pela interpretação e reespecificação de fatores (Hair et al., 2009), exemplificado na figura 1 . 
Tabela 1. Matriz dos Fatores Rotacionados

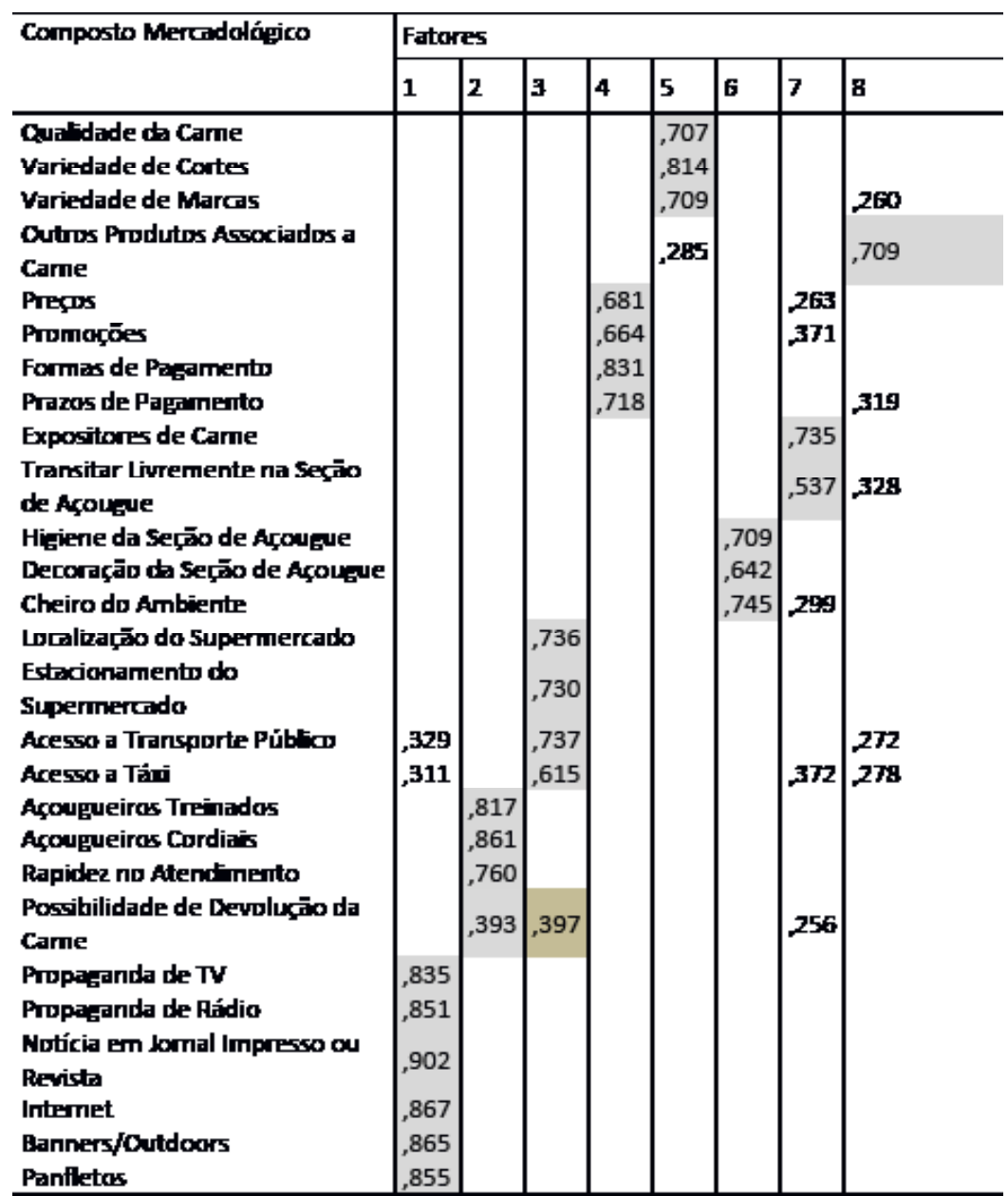

Fonte: Elaborado pelos próprios autores

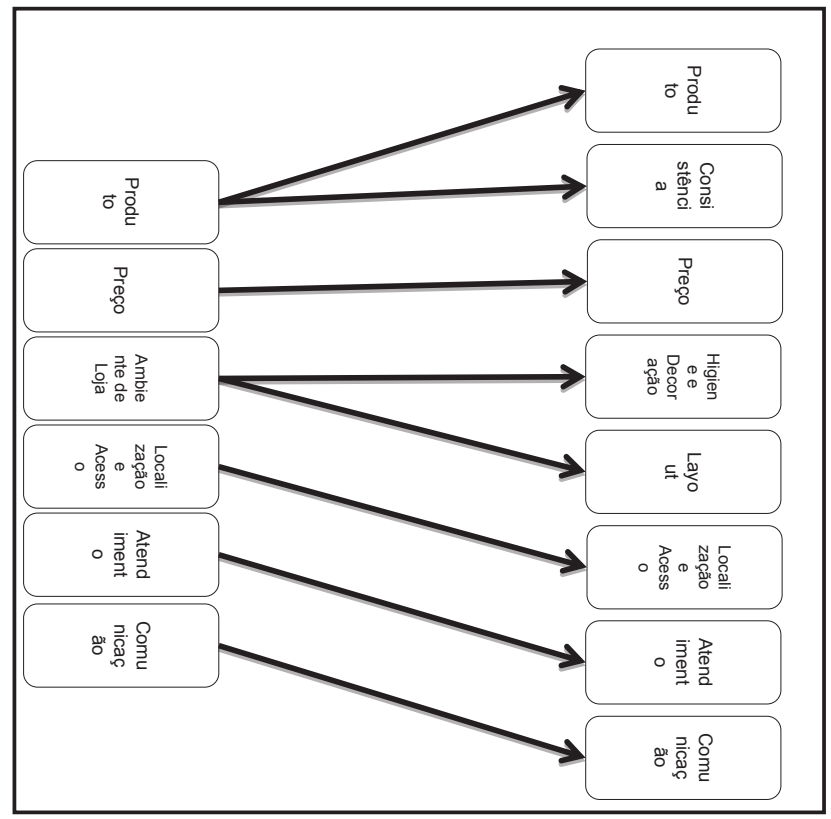

Figura 1. Resultados Obtidos da Análise Fatorial

Fonte: Elaborado pelos próprios autores 


\section{I Fator I - Comunicação}

O primeiro fator é composto pelas variáveis: propaganda de TV, propaganda de rádio, notícia em jornal impresso ou revista, internet, banners, outdoors e panfletos. Alguns desses elementos fazem parte do proposto por Parente et Barki (2006) como estratégias de comunicação e por Kotler (1993) como decisões de promoção.

Este fator possui o maior percentual de variância, sendo este valor $18,434 \%$, demonstrando o alto nível de explicação e correlação das variáveis em relação ao fator. Além disso, todas as variáveis possuem cargas fatoriais elevadas, entre 0,835 e 0,902 , conforme a tabela 2 .

Tabela 2. Comunicação

\begin{tabular}{c|c}
\hline Variáveis & Carga Fatorial \\
\hline Propaganda de TV & 0,835 \\
Propaganda de Rádio & 0,851 \\
Notícia em Jornal & 0,902 \\
Impresso ou Revista & \\
Internet & 0,867 \\
Banners/Outdoors & 0,865 \\
Panfletos & 0,855 \\
\hline
\end{tabular}

Fonte: Elaborado pelos próprios autores

O fator de comunicação está presente em outro formato de marketing mix, o composto mercadológico do e-varejo (Dennis et al., 2005). Diferente do "P" de promoção dos 4P's, a comunicação não está relacionada somente as investidas das empresas em difundir informações sobre produtos, preços, descontos, entre outros. Representa o conjunto de formas nas quais o consumidor pode manter o seu relacionamento por meio de opiniões, sugestões, reclamações e, assim, se sentir incluso no processo de comercialização.

Cinco elementos que formam o fator 1 são aqueles que contemplam o disposto como elemento promocional, pois estão relacionados a forma que os consumidores percebem o que as empresas desejam comunicar. Entretanto, a internet, item com a segunda maior carga fatorial, pode ser utilizada como meio de comunicação dos consumidores para a empresa pelo uso de e-mails, redes sociais, entre outros, justificando o rótulo atribuído e as correlações dadas ao fator.

\subsection{Fator 2 - Atendimento}

O segundo fator, conforme a tabela 25, é caracterizado pela presença das variáveis açougueiros treinados, açougueiros cordiais, rapidez no atendimento e possibilidade de devolução da carne, mantém sua principal característica, que é o uso e contato da força de vendas como meio de relacionamento entre empresa e cliente. Portanto, seu rótulo é denominado fator de atendimento.

Dentre as variáveis que o compõem, a possibilidade de devolução da carne possui carga fatorial muito abaixo de 0,7 . Além disso, possui maior carga quando associado ao terceiro fator, conforme destacado na tabela 1 . No entanto, levando em consideração a literatura, é possível observar que este possui maior correlação com as variáveis que foram o atendimento, não sendo facilmente associáveis às formas de acesso de um supermercado.

Tabela 3. Atendimento

\begin{tabular}{c|c}
\hline Variáveis & Carga Fatorial \\
\hline Açougueiros Treinados & 0,817 \\
Açougueiros Cordiais & 0,861 \\
$\begin{array}{c}\text { Rapidez no Atendimento } \\
\begin{array}{c}\text { Possibilidade de Devolução } \\
\text { da Carne }\end{array}\end{array}$ & 0,76 \\
\hline
\end{tabular}

Fonte: Elaborado pelos próprios autores

Dentre aquelas que possuem carga fatorial acima de 0,7 , a variável "rapidez no atendimento" é a que apresenta menor carga. Isso demonstra que a cordialidade e a especialização dos serviços dos açougueiros são os elementos determinantes no atendimento, embora a rapidez seja importante.

Embora não tenha sido necessário excluir a variável, devido aos testes que foram realizados, a possibilidade de devolução da carne não pode ser considerada uma variável de alta explicação em relação ao fator, descaracterizando a devolução como item importante do atendimento. A possibilidade de devolução é um item que consta apenas no trabalho de Nascimento (2006) como parte integrante da variável confiabilidade descrita em sua metodologia, correspondendo a confiança do cliente em comprar produtos sabendo que poderá 
substituí-los se for necessário, porém, esta não consta nos resultados como integrante de quaisquer fatores obtidos em sua análise fatorial. Deste modo, depreende-se a baixa importância atribuída a esta quando relacionada à compra e comercialização da carne bovina in natura.

\subsection{Fator 3 - Acesso}

O terceiro fator é composto por localização do supermercado, estacionamento do supermercado, acesso a transporte público e acesso a táxi, sendo denominado fator de localização e acesso. Esse fator contém apenas elementos das estratégias de localização dispostos por Teixeira (2007).

Tabela 4. Localização e Acesso

\begin{tabular}{c|c}
\hline Variáveis & Carga Fatorial \\
\hline $\begin{array}{c}\text { Localização do } \\
\text { Supermercado }\end{array}$ & 0,736 \\
$\begin{array}{c}\text { Estacionamento do } \\
\text { Supermercado }\end{array}$ & 0,73 \\
$\begin{array}{c}\text { Acesso a Transporte } \\
\text { Público }\end{array}$ & 0,737 \\
Acesso a Táxi & 0,615 \\
\hline
\end{tabular}

Fonte: Elaborado pelos próprios autores

O fator 3 , conforme a tabela 4 , apresenta uma variável com carga fatorial abaixo de 0,7: acesso a táxi. Sendo relacionado a acesso a fluxo de veículos e transporte (Teixeira, 2007).

No estudo realizado por Barki (2005), os resultados indicaram alta importância atribuída as estratégias de localização para uma das empresas em relação aos seus concorrentes. A alta concentração de lojas em uma mesma região é considerada um dos principais pontos fortes para prospecção de novos clientes, sendo este fato atribuído pelos gerentes das lojas ao serem entrevistados. Entretanto, para os respondentes deste estudo, a localização não foi considerada um dos itens de maior importância do composto mercadológico. Além disso, suas cargas fatoriais não possuem índices elevados. Isso demonstra o baixo índice de explicação das variáveis em relação ao fator, além disso, mostra que nenhuma das variáveis pode ser considerada como a essência do fator devido à uniformidade no valor de suas cargas.

\subsection{Fator 4 - Preço}

O quarto fator é constituído de preço, promoções, formas de pagamento e prazos de pagamento. Este fator é denominado fator de preço, não sendo diferente do proposto no composto mercadológico varejista, pois possui exatamente os mesmos elementos.

Tabela 5. Preço

\begin{tabular}{c|c}
\hline Variáveis & Carga Fatorial \\
\hline Preços & 0,681 \\
Promoções & 0,664 \\
Formas de Pagamento & 0,831 \\
Prazos de Pagamento & 0,718 \\
\hline
\end{tabular}

Fonte: Elaborado pelos próprios autores

O fator 4, conforme tabela 5, é formado pelas estratégias de preço, possui duas variáveis com cargas fatoriais abaixo de 0,7 . No entanto, devido a sua proximidade a esse valor, observa-se apenas que, para esse fator, ambas possuem um nível de explicação menor do que as formas de pagamento e prazos de pagamento.

Entretanto, a variável "formas de pagamento" é aquela com maior carga fatorial, portanto, explica melhor a natureza do fator de preço, tendo maior importância do que as outras quando se trata de estratégias de preço para a comercialização da carne bovina no varejo supermercadista.

Em pesquisa realizada por Nascimento (2006), a variável "forma de pagamento" obteve avaliação positiva maior do que outros itens, inclusive o preço. Além disso, para o mesmo autor, alguns consumidores que fizeram parte da pesquisa conseguem perceber a transmissão de preços ao longo da cadeia, questionando o quanto o preço é justo para eles quando há diminuição dos custos para os meios de produção. Isso demonstra a preocupação com o preço e a necessidade de haver facilidade de pagamento que não somente "à vista". Sendo assim, a variável que caracteriza essencialmente o fator de preço é a forma de pagamento.

\subsection{Fator 5 - Produto}

$\mathrm{O}$ quinto fator, caracterizado como fator de produto, é formado pela qualidade da carne, 
variedade de cortes e variedade de marcas. Este fator, diferente das outras estratégias propostas por Kotler (1993), Barki (2005), Parente et Barki (2006) e Las Casas (2007), não tem o elemento das estratégias de consistência, que é a associação de diversos produtos secundários a um principal, dado no instrumento de coleta como "outros produtos associados a carne", pois este elemento obteve alto valor de carga fatorial de modo isolado, sem correlação com quaisquer outros elementos.

Tabela 6. Produto

\begin{tabular}{c|c}
\hline Variáveis & Carga Fatorial \\
\hline Qualidade da Carne & 0,707 \\
Variedade de Cortes & 0,814 \\
Variedade de Marcas & 0,709 \\
\hline
\end{tabular}

Fonte: Elaborado pelos próprios autores

O fator de produto possui todas as variáveis que o compõem com carga fatorial acima de 0,7 . A essência do fator é mais bem explicada pela variedade de cortes. A qualidade da carne e variedade de marcas também são itens importante, porém, não no mesmo nível da variedade dos cortes. Isso mostra que dentre as estratégias de produto ligadas à comercialização da carne bovina no varejo, aquela que prevalece é a amplitude.

O destaque da variável variedade de cortes também acontece no estudo realizado por Villalobos (2010) com consumidores chilenos. Entretanto, é importante destacar que o alto nível de importância foi atribuído aos cortes regionais, considerado pelos respondentes uma compra de baixo risco, devido ao seu conhecimento sobre origem e manuseio. Para Nascimento (2006), o corte da carne foi relacionado ao atendimento, pois os consumidores realizavam a aquisição de peças graúdas e inteiriças para que açougueiros pudessem realizar os cortes desejados.

\subsection{Fator 6 - Higiene e Decoração}

O sexto fator foi denominado higiene e decoração, pois se constitui de higiene da seção de açougue, decoração da seção de açougue e cheiro do ambiente. Este fator surge do desmembramento das estratégias de ambiente de loja e é formado apenas por elementos nos quais o consumidor estabelece sua percepção por meio das condições sanitárias da loja e de seu aspecto decorativo, dado por cores, fotos e outros itens que estimulam visualmente o cliente durante o ato da compra, sem ter apelo específico ao produto ou sua forma de exposição.

Tabela 7. Higiene e Decoração

\begin{tabular}{c|c}
\hline Variáveis & Carga Fatorial \\
\hline $\begin{array}{c}\text { Higiene da Seção de } \\
\text { Açougue }\end{array}$ & 0,709 \\
$\begin{array}{c}\text { Decoração da Seção de } \\
\text { Açougue }\end{array}$ & 0,642 \\
Cheiro do Ambiente & 0,745 \\
\hline
\end{tabular}

Fonte: Elaborado pelos próprios autores

O fator 6 , apresentado pela tabela 7 por meio de três variáveis, possui apenas uma com nível inferior a 0,7 , sendo esta a decoração da seção de açougue. $O$ fato de esta variável possuir menor carga fatorial e, portanto, explicar menos o fator se dá pelo alto nível de importância atribuído aos aspectos sanitários da seção de açougue, ligados a higiene e cheiro. No entanto, ressalta-se o fato de nenhuma variável ter carga elevada acima de 0,8 . Desse modo, corrobora com o disposto na tabela 1 , onde a variância percentual atribuída após a rotação é a terceira menor entre os oito fatores.

O cheiro do ambiente, variável com maior carga fatorial, é disposto de modo distinto em outros estudos. Segundo Barcellos et Ferreira (2003), o cheiro está relacionado ao produto, tendo sido a este atribuído alto valor de importância dos respondentes. Observa-se também que, para Mazzuchetti et Batalha (2005), o cheiro do ambiente não é citado como elemento relevante a compra. No entanto, ainda para estes autores, a higiene da seção de açougue é preponderante para todo o processo de compra da carne, afetando a percepção do consumidor em relação à qualidade do produto.

\subsection{Fator 7 - Layout}

O sétimo fator se constitui exatamente dos elementos ligados à forma de exposição da carne bovina e pelo tráfego na seção de açougue, sendo esses elementos os expositores de carne e "transitar livremente na seção de açougue." Esses elementos, desmembrados das estratégias de ambiente de loja, se diferenciam dos demais que compõem o fator anterior por serem relacionados ao layout da loja ou seção de venda de carnes e a forma de expo- 
sição do produto, por isso, foram denominados fator de layout.

Tabela 8. Layout

\begin{tabular}{c|c}
\hline Variáveis & Carga Fatorial \\
\hline Expositores de Carne & 0,735 \\
$\begin{array}{c}\text { Transitar Livremente na } \\
\text { Seção de Açougue }\end{array}$ & 0,537 \\
\hline
\end{tabular}

Fonte: Elaborado pelos próprios autores

A tabela 8, que apresenta o sétimo fator, mostra apenas duas variáveis em sua dimensão e, ainda, uma delas tem valor inferior a 0,7 . Isso demonstra que a variância percentual após a rotação é a segunda menor entre os fatores, justificando baixo nível de explicação deste fator e de correlação entre variáveis. Portanto, a natureza do fator 7 é explicada essencialmente pela variável expositores de carne.

\subsection{Fator 8 - Consistência}

O oitavo fator, denominado fator de consistência, possui apenas um elemento que é "outros produtos associados à carne." Esse fator representa a consistência atribuída ao conjunto de produtos que podem ser relacionados à carne bovina durante o ato da compra, como carvão, sal, temperos, entre outros. A existência de tais produtos reflete o conceito de mix de produtos, porém, também mostra relação entre as diversas categorias ofertadas, as quais podem ser direcionadas a um nicho de mercado específico ou, ainda, variar de acordo com o formato de loja.

Tabela 9. Consistência

\begin{tabular}{c|c}
\hline Variáveis & Carga Fatorial \\
\hline $\begin{array}{c}\text { Outros Produtos } \\
\text { Associados a Carne }\end{array}$ & 0,709 \\
\hline
\end{tabular}

Fonte: Elaborado pelos próprios autores

A tabela 9 apresenta o único fator que possui uma única variável: fator de consistência. Partindo da prerrogativa que apenas uma variável pode explicar um fator, sua carga fatorial é aceitável, pois está acima de 0,7.

Ainda, está relacionado às estratégias de consistência do mix de produto, ligado direta- mente às estratégias de produto. No entanto, sua importância está atribuída aos produtos acessórios à carne bovina, como disposto anteriormente.

Justifica-se sua separação do fator de produto em decorrência da não relação exclusiva ao produto, de modo que esta estratégia não está ligada às características tangíveis da carne bovina in natura.

\section{CONCLUSÕES}

Os resultados provenientes da análise fatorial mostram diferenças perceptíveis em relação a outros modelos de compostos mercadológicos. Algumas destas diferenças podem ser associadas à comercialização da carne bovina, obstante a concepção industrial de Neil Borden (1964) e dos tradicionais 4P's de Jerome Maccarthy. Além disso, o direcionamento a um produto específico mostrou estruturas subjacentes ao composto proposto por Barki et Parente (2006), mesmo este também sendo associado ao varejo.

Entre as principais diferenças entre o modelo proposto e os outros compostos destaca-se o oitavo fator, denominado fator de consistência. Diferente das estratégias de produto comuns aos 4P's, este fator não está associado diretamente à amplitude e à profundidade. A ausência de relação desse fator com as características tangíveis da carne bovina, como qualidade e variedade de cortes e marcas, mostra a importância da concepção de mix de produtos associados à carne. Isto se dá por meio da associação de produtos diversos a um principal, como o carvão, sal e temperos, tradicionalmente relacionados com o preparo de alimentos.

Além da consistência, o sétimo fator, denominado fator de layout, é oriundo do desmembramento das estratégias de ambiente de loja. Porém, não se diferencia significativamente do nomeado como "P" de place, praça ou ponto de venda, pois suas características estão ligadas diretamente ao espaço onde são realizadas as vendas, sem conexão com o produto por meio da ideia do bom armazenamento ou das condições sanitárias. $\mathrm{O}$ foco deste fator está no consumidor e no conforto do local onde ele está buscando conhecer as ofertas do supermercado, podendo transitar livremente e se observando o produto exposto.

\section{REFERÊNCIAS}

BARCELLOS, M. et FERREIRA, G. (2003), 
"Experts e consumidores: duas visões sobre o processo de compra de carne bovina", artigo apresentado no IV Pensa Conference, São Paulo, SP, 2003.

BARKI, E. (2005), Estratégias de empresas varejistas direcionadas para a baixa renda: um estudo exploratório, Dissertação de Mestrado em Administração de Empresas, Escola de Administração de Empresas da Fundação Getúlio Vargas, São Paulo, SP.

BINKLEY, J. e CONNOR, J. (1998) "Grocery Market Pricing and The New Competitive Environment", Journal of Retailing, Vol. 74 No. 2, pp. 273-294.

BORDEN, N.(1964) "The concept of the Marketing Mix”, Journal of Advertising Research, pp. 197-208.

BORTOLI, P. (2008), Plano de marketing da lanchonete RIB's. Monografia de Bacharelado em Administração da Universidade Federal do Rio Grande do Sul). Porto Alegre, RS.

COBRA, M. (2000), Marketing de serviço financeiro. 1 ed.,, Cobra, São Paulo, SP.

\section{CONSTANTINIDES, E. (2006) "The Marketing}

Mix Revisited: towards the 21st century marketing", Journal of Marketing Management, vol. 22, pp. 40738.

DENNIS, C. et al. (2005), "Sale the Seven Cs Teaching/training Aid For The e-retail mix, International Journal of Retail and Distribution Management", Vol. 3, No. 33, pp. 179-193, Bingley, UK.

FEUZ, D., UMBERGER, W. (2001), "Consumer Willingness-to-Pay for Flavor in Beef Steaks: An Experimental Economics Approach". Cornhusker Economics, Paper 30, disponível em http://digitalcommons.unl.edu/cgi/viewcontent. cgi? article $=1029 \&$ context $=$ agecon_cornhusker $>$ (Acesso em 10 de outubro de 2013).

FIPECAFI. (2011), Análise multivariada: para os cursos de administração, ciências contábeis e economia. 1 ed., Atlas, São Paulo, SP.

GOI, C. (2009), "A Review of Marketing Mix: 4P's or more?, International Journal of Marketing Studies", Vol. 1, No. 1,pp. 1-15, Markham, CA.

GOSLING, M.; SOUZA, B. (2007), "Mix de marketing de serviços, satisfação e lealdade de clientes de um banco de varejo: um estudo multigrupos". Trabalho apresentado ao $31^{\circ}$ Encontro da Associação Nacional de Pós-graduação e Pesquisa em Administração, Rio de Janeiro, RJ,22 a 26 de setembro de 2007, disponível em http://www.anpad.org. br/diversos/trabalhos/EnANPAD/enanpad_2007/ MKT/2007_MKTD1489.pdf (Acesso em 05 de outubro de 2013).

HAIR, J., ANDERSON, R., TATHAM, R., BLACK, W. (2009), Análise multivariada de dados. 6 ed., Bookman, Porto Alegre, RS.

KIRSCH, D. (2010), Comportamento do consumidor: fatores que determinam a decisão de compra dos clientes no supermercado vila Irma redefort, Monografia de bacharelado em Administração da Universidade Feevale, Novo Hamburgo, RS.

KOTLER, P. (2009), Marketing para o século XXI: como criar, conquistar e dominar mercados. 1 ed., Ediouro, São Paulo, SP.

KOTLER, P., ARMSTRONG, G. (1993), Princípios de marketing. 1 ed., Prentice Hall, Rio de Janeiro, RJ.

LAS CASAS, A. (2007), Estratégias de marketing para varejo: inovações e diferenciações estratégicas que fazem a diferença no marketing de varejo. 1 ed., Novatec, São Paulo, SP.

MAZZUCHETTI, R., BATALHA, M. (2005), "O comportamento do consumidor em relação ao consumo e às estruturas de comercialização da carne bovina na região de Amerios/PR", Revista Varia Scientia, Vol. 04, No. 08, pp. 25-43, Cascavel, PR.

NASCIMENTO, C. (2006), Fatores determinantes da qualidade percebida na comercialização de carne bovina fresca em supermercados de Campo Grande/ MS, Dissertação de Mestrado em Agronegócios do Programa de Pós-Graduação Multiinstitucional, UFMS, UNB, UFG, Campo Grande, MS, Brasília, DF, Goiânia, GO.

NEVES, M. (2000), "Redes agroalimentares \& marketing da carne bovina em 2010", Trabalho apresentado no $4^{\circ}$ Congresso brasileiro das raças zebuínas. Uberaba, MG., 26 a 28 de Outubro de 2000, disponível em http://www.markestrat.org/ pt-br/publicacao.php?id_item=139. (Acesso em 02 de setembro de 2013).

PARENTE, J. (2008), O varejo de alimentos 
para consumidores de baixa renda no Brasil. 1 ed. FGV/Eaesp , São Paulo, SP, disponível em http://bibliotecadigital.fgv.br/dspace/bitstream/ handle $/ 10438 / 2916 /$ Rel162008.pdf?sequence $=1$. (Acesso em 15 de julho de 2013).

PARENTE, J; BARKI, E. (2006) "Varejo na baixa renda". Marketing, Vol. 05, No 1, pp. 39-43.

PARENTE, J.; KATO, H. (2001), "Área de influência: um estudo no varejo de supermercados". Revista de administração de empresas, Vol. 41, No. 2, pp. 46-53.

PAULA, S. (2006), Estratégias de marketing utilizadas pelas empresas varejistas localizadas no centro comercial de rua baixa dos sapateiros da cidade do salvador, que elegem as classes de renda c, d e e como mercado-alvo, Dissertação do Master of Science em Marketing e Gestão Empresarial - Curso de Pós-Graduaçao da Universidade Internacional de Lisboa, Lisboa, PT.

PRAXEDES, K. (2007), Análise do composto de marketing no segmento varejista de padarias: um estudo em Natal-RN, Dissertação do Mestrado em Administração - Programa de Pós-Graduação da Universidade Federal da Paraíba, João Pessoa, PB.

SCHEWE, C. (1982), Marketing: conceitos, casos e aplicações. 1 ed., MaGraw, São Paulo, SP.

SILVEIRA, R., SINEM, M. (2009), "Quem te viu, quem te vê: as mudanças do composto mercadológico do varejo de shopping centers da região do vale do itajaí/sc durante a sua existência". Revista de Administração da UFSM, Vol.2, No. 2, pp. 214-34, Santa Maria, RS.

SOUZA, L. (2009), Comunicação e cultura do consumo: ponto de venda e design - variáveis influenciadoras no comportamento do consumidor, Dissertação do Mestrado em Ciência da Comunicação do Programa de Pós-graduação em Ciências da Comunicação, Universidade de São Paulo, São Paulo, SP.

TEIXEIRA, M. (2007), As ações organizacionais e estratégias mercadológicas das três maiores redes varejistas supermercadistas no Brasil. Dissertação do Mestrado em Administração e Desenvolvimento Empresarial, Universidade Estácio de Sá, Rio de Janeiro, RJ.
VIDAURRE, W., FILHO, D. (2003), "Communication With Consumer In Food Retail: the case of supermarkets", Trabalho apresentado no IV Congresso Internacional de Economia e Gestão de Redes Agroalimentares. Ribeirão Preto, SP,29 -31 de outubro de 2003, disponível em http://www.fearp. usp.br/egna/Por/aprovados.htm. (Acesso em 20 de julho de 2013).

VILLALOBOS, P. (2010), "Beef Consumer Preferences In Chile: importance of quality attribute differentiators on the purchase decision". Chilean Journal of Agricultural Research, Vol. 70, No. 01, pp. 85-94, Chillán, CL. 